\title{
Characterizing Surface Albedo of Shallow Fresh Snow and Its Importance for Snow Ablation on the Interior of the Tibetan Plateau
}

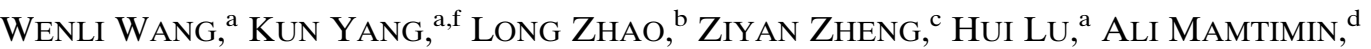 \\ Baohong Ding, ${ }^{\mathrm{e}}$ Xin Li, ${ }^{\mathrm{e}, \mathrm{f}}$ Lin ZhaO, ${ }^{\mathrm{g}}$ Hongyi Li, ${ }^{\mathrm{h}}$ TaO Che, ${ }^{\mathrm{h}}$ And John C. MoOre ${ }^{\mathrm{i}, \mathrm{j}}$ \\ ${ }^{\mathrm{a}}$ Ministry of Education Key Laboratory for Earth System Modeling, Department of Earth System Science, \\ Tsinghua University, Beijing, China \\ ${ }^{\mathrm{b}}$ School of Geographical Sciences, Southwest University, Chongqing, China \\ ${ }^{\mathrm{c}}$ Key Laboratory of Regional Climate-Environment Research for East Asia, Institute of Atmospheric Physics, \\ Chinese Academy of Sciences, Beijing, China \\ ${ }^{\mathrm{d}}$ Institute of Desert Meteorology, China Meteorological Administration, Urumqi, China \\ e National Tibetan Plateau Data Center, Institute of Tibetan Plateau Research, Chinese Academy of Sciences, \\ Beijing, China \\ ${ }^{\mathrm{f}}$ CAS Center of Excellence for Tibetan Plateau Earth Science, Institute of Tibetan Plateau Research, Chinese \\ Academy of Sciences, Beijing, China \\ ${ }^{\mathrm{g}}$ School of Geographical Sciences, Nanjing University of Information Science and Technology, Nanjing, China \\ ${ }^{\mathrm{h}}$ Heihe Remote Sensing Experimental Station, Cold and Arid Regions Environmental and Engineering \\ Research Institute, Chinese Academy of Sciences, Lanzhou, China \\ ${ }^{\mathrm{i}}$ College of Global Change and Earth System Science, Beijing Normal University, Beijing, China \\ ${ }^{\mathrm{j}}$ Arctic Centre, University of Lapland, Rovaniemi, Finland
}

(Manuscript received 20 August 2019, in final form 15 January 2020)

\begin{abstract}
Snow depth on the interior of Tibetan Plateau (TP) in state-of-the-art reanalysis products is almost an order of magnitude higher than observed. This huge bias stems primarily from excessive snowfall, but inappropriate process representation of shallow snow also causes excessive snow depth and snow cover. This study investigated the issue with respect to the parameterization of fresh snow albedo. The characteristics of TP snowfall were investigated using ground truth data. Snow in the interior of the TP is usually only some centimeters in depth. The albedo of fresh snow depends on snow depth, and is frequently less than 0.4 . Such low albedo values contrast with the high values $(\sim 0.8)$ used in the existing snow schemes of land surface models. The SNICAR radiative transfer model can reproduce the observations that fresh shallow snow has a low albedo value, based on which a fresh snow albedo scheme was derived in this study. Finally, the impact of the fresh snow albedo on snow ablation was examined at 45 meteorological stations on TP using the land surface model Noah-MP which incorporated the new scheme. Allowing albedo to change with snow depth can produce quite realistic snow depths compared with observations. In contrast, the typically assumed fresh snow albedo of 0.82 leads to too large snow depths in the snow ablation period averaged across 45 stations. The shallow snow transparency impact on snow ablation is therefore particularly important in the TP interior, where snow is rather thin and radiation is strong.
\end{abstract}

\section{Introduction}

The average elevation of the Tibetan Plateau (TP), the "roof of the world," is more than $4000 \mathrm{~m}$ above the sea level. Strong uplifting of the TP since the Neogene has produced a natural environment distinctive from other regions of the world. Characteristics include large seasonal and very large diurnal variations of temperature,

Corresponding author: Kun Yang, Dr., yangk@tsinghua.edu.cn intense solar radiation, numerous rivers and lakes, extensive glacier and permafrost, and abundant biodiversity (Zhou et al. 2000). The TP has experienced warming at a higher rate than the global mean especially during the 1980s-2000s (Liu and Chen 2000), and is expected to warm faster in the future climates as well (IPCC 2013). This makes the cryosphere and ecosystem of the TP particularly vulnerable, but until now the mechanisms of glacier retreat, permafrost degradation, lake expansion and/or shrinkage, vegetation succession along with the feedbacks 
to the atmosphere are far from understood (Wu et al. 2016; Sun et al. 2018; Yang et al. 2018). More comprehensive station observations are expected to deepen our understanding of the land-atmosphere interactions on TP, where meteorological stations are very sparse.

In this unique region, snow plays a crucial role in the water and energy cycles, and can have profound feedbacks to climate (Zhang 2005). Snow modifies the ground energy balance by its high albedo and also provides strong insulation due to its low thermal conductivity. The spatial and temporal variation of TP snow cover at various scales affects both the local weather status and the Asian summer monsoon (Blanford 1884; Xiao and Duan 2016). Snowmelt in spring also serves as an important water supply to some large river systems on the TP (Han et al. 2019). Snow is therefore a key component in the Tibetan climate system.

The characteristics of snow on the TP is quite different from that in the circum-Arctic region (Wang et al. 2018). Due to the low latitude of the TP, the solar radiation is strong throughout the year, and snow ablates quickly on clear and dry winter and spring days. The snow is rather heterogeneous across the TP, thick snow from tens of centimeters to several meters on the mountains and shallow snow of only a few centimeters across the interior (Qin et al. 2006). In addition, where the wind is strong, blowing snow both leads to patchy snowpack and bare ground, and reduces snow accumulation by sublimation (Shao et al. 2017).

State-of-the-art reanalysis datasets can produce 10 times the observed snow depth in the TP interior (Orsolini et al. 2019). The huge bias stems primarily from too much snowfall in the reanalysis model (Orsolini et al. 2019). However, various snow processes that might be important may also be missing or misrepresented. These include blowing snow sublimation (Orsolini et al. 2019), snow patch effects, and dust deposition (Qian et al. 2011). Current snow schemes used in land surface and reanalysis models have emphasized development of increasing number of snow layers, dynamic evolution of snow density and thermal conductivity (Wang et al. 2016). These are important processes to simulate snow depth and the insulation effect on the ground (Wang et al. 2016). Another key component of the snow scheme is the parameterization of snow surface albedo, which greatly determines the ground surface energy balance. Although many snow schemes assume fresh snow albedo as high as $\sim 0.8$, Giddings and LaChapelle (1961) and McKay and Gray (1981) showed that the combined albedo of shallow snow over soil can be far lower than 0.8 , and only achieves the value of 0.8 after accumulation of several centimeters of snow depth.

Snow albedo is described by various models and schemes of varying complexity. Table 1 summarizes the current fresh snow albedo schemes used by state-of-the-art
TABLE 1. Fresh snow albedo schemes applied in state-of-the-art land surface models.

\begin{tabular}{lcl}
\hline \multicolumn{1}{c}{ Model } & Fresh snow albedo & \multicolumn{1}{c}{ Reference } \\
\hline BATS & 0.78 & Dickinson et al. (1993) \\
CLM3.5-CLM5.0 & SNICAR & Oleson et al. (2010) \\
Noah-MP-BATS & 0.8 & Niu et al. (2011) \\
Noah-MP-CLASS & 0.84 with fresh snow & Niu et al. (2011) \\
& depth $>1 \mathrm{~cm}$ & \\
CoLM & 0.78 & Dai et al. (2001) \\
Noah & 0.75 & Chen et al. (1996) \\
SiB2 & 0.8 for visible & Sellers et al. (1996) \\
& 0.4 for near-infrared & \\
ISBA & 0.85 & Douville et al. (1995) \\
HTESSEL & 0.8 & Orsolini et al. (2019) \\
\hline
\end{tabular}

land surface models. Almost all the land surface models adopt simplified snow albedo schemes, which assume a high fixed value as the fresh snow albedo $(0.78$ for HTESSEL, 0.8 for CoLM, 0.84 for CLASS, and 0.8 for BATS in Noah-MP, etc.) and use a snow aging factor to describe the decrease of snow albedo with time. The CLASS scheme in Noah-MP includes the snow depth in fresh snow albedo calculation only when snowfall amount is less than $1 \mathrm{~mm}$ and sets a lower bound of snow albedo as 0.55 (see details given in the appendix). The CLM uses the Snow and Ice Aerosol Radiation model (SNICAR) to calculate snow albedo. This model calculates the radiation transfer in snow with the consideration of snow grain size and snow depth (Flanner and Zender 2006), and outputs the spectral reflectance and broadband albedo. SNICAR is excellent for investigating the impact of light-absorbing impurities on snow aging and has been widely applied in remote sensing and pointscale albedo simulations (Singh et al. 2018; He et al. 2018; Lawrence et al. 2011; Flanner et al. 2007; Flanner and Zender 2005). However, SNICAR is computationally expensive when it comes to high-resolution or long time series of climate simulations. Hence, a simplified version of SNICAR is preferable for regional land surface modeling.

These listed fixed high fresh snow albedo parameters (Table 1) are designed for thick snow, but the snow cover over most of TP is quite shallow which can come and go several times a year and thus it is usually difficult to explicitly distinguish the accumulation and ablation seasons. Snow of only a few centimeters can be somewhat transparent, so the albedo of fresh shallow snow is prone to be affected by the ground beneath. While SNICAR can describe the effect of bare ground on the snow albedo, other schemes with fixed fresh snow albedo values $(\sim 0.78-0.9)$ run the risk of being too high for the shallow snow. Thus, an important question here is how the albedo of fresh shallow snow differs from that 


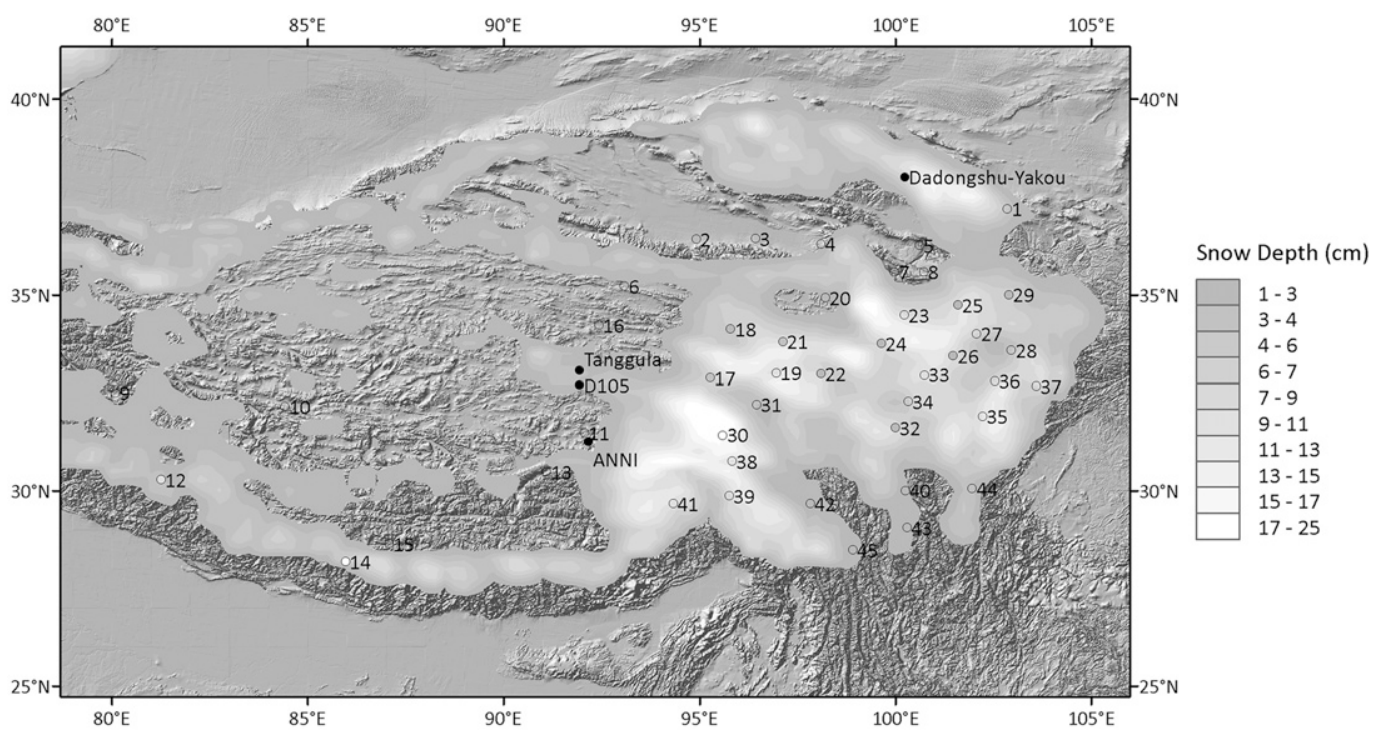

FIG. 1. The location of the four experimental stations with hourly/half hourly measurement on the Tibetan Plateau (black dots). The location of 45 meteorological stations (circles), and the average of the observed 2012-14 Jan snow depth (filled). The shade is the January snow depth averaged through 2012 to 2014 using the microwave satellite data (Che et al. 2008). The background is the topography of the Tibetan Plateau represented by the hill shade from SRTM, provided by Geospatial Data Cloud site, Computer Network Information Center, Chinese Academy of Sciences.

of fresh thick snow, and how the albedo difference affects the snow ablation on the interior of the TP.

The aim of this study is to investigate the characteristics of fresh snow albedo on the TP interior and its effect on snow ablation. We used observations of upward/downward shortwave radiation and snow depth at four experimental stations (section 2) to investigate the characteristics of snow depth and albedo (section 3). We demonstrated that the SNICAR model can reproduce the observed variability of snow albedo in shallow snow cases and then developed a new fresh snow albedo scheme which was fitted with the SNICAR simulations (section 4). Finally, we tested the new scheme in Noah-MP and performed validation with the snow depth observed at 45 meteorological stations on the TP (section 5).

\section{Data and models}

\section{a. Observations at experimental stations}

The experimental station observations were used to analyze the characteristics of snow depth and albedo in the TP. Ground truth from station-observed snow accumulation and ablation with simultaneous radiation and snow depth data on the TP is quite few. We used all data that are accessible, which means that the observation periods are not the same across the stations. These stations include ANNI-AWS (1 October 2002-14 August 2004 hourly), D105 (1 October 2002-28 November 2004, hourly) obtained through CEOP (Coordinated Enhanced Observing Period) Asia-Australia monsoon project (CAMP) on the TP (Koike 2004; Ma et al. 2005), Tanggula Mountain Station (1 January 2012-31 December 2012, half-hourly) (Zhao et al. 2017; Zhao and Sheng 2019), and Dadongshu-Yakou Station (17 December 2013-31 August 2016 hourly) (Che et al. 2019; Li et al. 2019). Their locations are shown in Fig. 1. The altitudes of the four stations are higher than $4000 \mathrm{~m}$, with a cold and dry climate that is typical on the TP. Among them, three stations (ANNI-AWS, D105, Tanggula) are located in the interior of the TP and one (Dadongshu-Yakou) is located in the Qilian Mountains, Northeast TP. The mountain station experiences more snowfall events than the three interior stations, but they share similar albedo features when snow is shallow.

The measurements are described in detail in the corresponding references. The four-component radiation sensor at Dadongshu-Yakou and Tanggula station is a CNR4. The shortwave radiation sensor at D105 and ANNI station is a CM21 and the longwave radiation sensor is a precision infrared radiometer. Radiation data were recorded every $30 \mathrm{~min}$ or $1 \mathrm{~h}$ by the radiometers installed at a height of $1 \mathrm{~m}$ at the Dadongshu-Yakou station, $2 \mathrm{~m}$ at the Tanggula station, and at $1.28 \mathrm{~m}$ for upward shortwave/longwave radiation and $1.58 \mathrm{~m}$ for downward shortwave/longwave radiation at both the D105 and ANNI station.

All the measurements have been quality controlled as far as possible. Snow depth can be difficult to reliably 
ascertain, especially in harsh and rugged terrain and therefore we made cross checks of data quality. Observed meteorological and snow depth data with good quality are expected to meet all of the following requirements: 1) the upward longwave radiation must be less than $315.6 \mathrm{~W} \mathrm{~m}^{-2}$, that is, the ground surface temperature cannot be above $0^{\circ} \mathrm{C}$ when snow exists; 2) air temperature must be less than $5^{\circ} \mathrm{C}$ during snowfall, since snowfall can happen on the TP when air temperature is above $0^{\circ} \mathrm{C} ; 3$ ) measured snow depth should be greater than $1 \mathrm{~cm}$, which is the measurement uncertainty of snow depth; and 4) observed snow depth increases when snowfall is recorded-this requirement was not applied to Tanggula station because precipitation events were not recorded during all the measurement period. Observed snow albedo was calculated as the ratio of upward to downward shortwave radiation following Che et al. (2019). To further eliminate the impact of solar angle on albedo, we took averages between 1000 and 1400 local time of albedo, snow depth, air temperature, and precipitation, as the "daily" values for the four experimental sites in the statistical analysis.

\section{b. Observations at routine meteorological stations}

Snow depth is measured at routine meteorological stations of China Meteorological Administration (CMA) on the TP. The station data were used to validate the impact of fresh snow albedo on the snow ablation simulation.

Daily mean datasets of air temperature, precipitation, relative humidity, pressure and snow depth observed during 2012-14 were used. The observed precipitation was prone to be underestimated due to the wind. We therefore performed bias correction according to the methodology described in Ye et al. (2004). The daily snow depth was recorded at 0800 local time of each day. We further quality controlled the data to eliminate stations with questionable data. A station was removed if there were frequent missing data or there were discrepancies in the time occurrences between the observed precipitation and snow depth. After quality control, there are 45 meteorological stations available (Fig. 1).

The forcing data to drive the land surface model Noah-MP (see section 2c) were made available through fusing the daily mean of the station data with the diurnal cycle of the China Meteorological Forcing Dataset (CMFD). The CMFD at $0.1^{\circ}$ spatial resolution and at $3 \mathrm{~h}$ temporal resolution was developed by the Institute of Tibetan Plateau Research, Chinese Academy of Sciences (Yang et al. 2010; He et al. 2020). CMFD includes precipitation, downward shortwave radiation, downward longwave radiation, 2-m air temperature, specific humidity, wind speed, and surface pressure. Missing air temperatures in the meteorological observation were replaced with the CMFD grid's air temperature and the air temperature lapse rate $\left(6.5^{\circ} \mathrm{km}^{-1}\right)$ was used to correct the impact of altitude difference between CMFD grids and stations. Missing pressures were replaced with the observed pressure of the previous day. Missing wind speed and relative humidities were replaced with the grid values of CMFD. The meteorological specific humidity was then calculated with the corrected air temperature, pressure and relative humidity. Downward shortwave and longwave radiation data were not provided by CMA and they were directly extracted from CMFD.

\section{c. Models}

We used two models: SNICAR was used to demonstrate its capability for reproducing the observed characteristics of fresh snow albedo, and the Noah-MP land surface model was used to verify the impact of fresh snow albedo on the TP snow ablation.

SNICAR is a physically based radiative transfer model for snow, which incorporates a two-stream radiative transfer solution from Toon et al. (1989). Following the adapted calculation methodology from Wiscombe (1980), optical properties from Mie theory are calculated for each snow layer and spectral band (Flanner and Zender 2006; Flanner et al. 2007). With the inclusion of extinction optical depth, SNICAR can consider the impact of snow depth on albedo. SNICAR simulates solar absorption both in the snow layers and the underlying substrate. Snow aging is calculated with the ice effective grain size, which conserves the specific surface area (Grenfell and Warren 1999). The change in effective grain size is caused both by the dry and wet snow processes, including liquidwater-induced metamorphism, refreezing of liquid water, the addition of freshly fallen snow, and dry snow metamorphism. SNICAR can reproduce some typically observed phenomena like rapid snow aging from the combination of warm snow, large temperature gradient, and low density.

Noah-MP is a unique multiparameterization land surface model that allows the user to combine different schemes for simulating individual land processes (Niu et al. 2011). The snow model in Noah-MP is of up to three layers, depending on the snow depth. Snow layer temperature, snow height, snow water equivalent, and snow cover fraction have to meet the requirement of energy and mass balance. Snow layer division and combination, liquid water storage and melt/refreeze capability, and snow interception by vegetation are all described in the model.

There are two options for snow albedo scheme in Noah-MP: CLASS and BATS. The equations of the two 

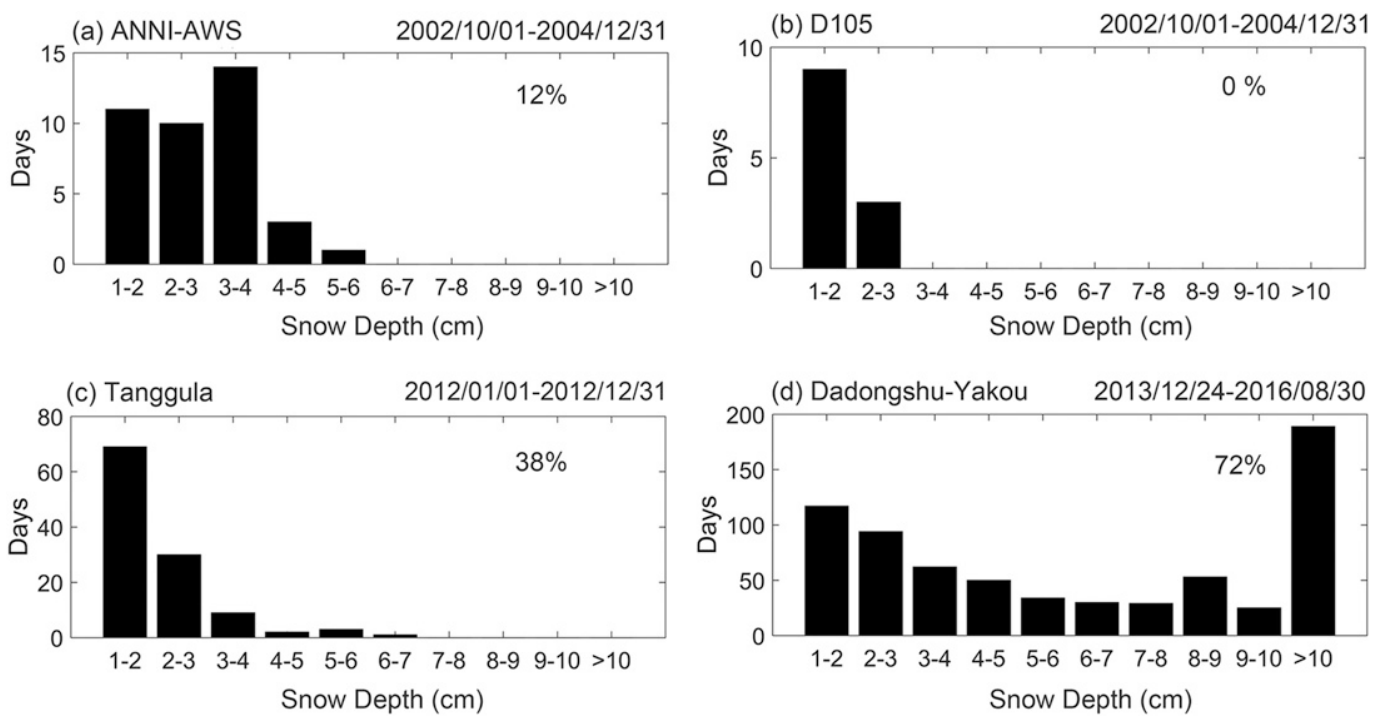

FIG. 2. Histogram of the snow depth at each of the four stations. The fraction of winter period (DJF) with snow depth $>1 \mathrm{~cm}$ is labeled in the upper-right corner; the fraction is zero for D105 station because there are the only few days with snow cover for D105 station occurring from March to June.

snow albedo schemes are listed in the appendix. NoahMP calculates albedo for both the visible and nearinfrared wave bands under both direct and diffuse radiation. The snow albedo scheme of CLASS for the two wave bands under both direct and diffuse radiation is the same. The fresh snow albedo of CLASS is 0.84 if the new fallen snow mass $>1 \mathrm{~mm}$. Below the critical value the fresh snow albedo is an average of old snow albedo and 0.84 , weighted by the old and new snow mass. Snow ages as an exponential function with time and the minimum value of snow albedo is 0.55 . In BATS, the fresh snow albedo for the visible band is 0.95 and the near-infrared band is 0.65 . The snow albedo under direct radiation is a linear function of the snow albedo under diffuse radiation, and snow aging is a function of time, ground temperature and snow mass. Neither of the schemes strictly describes the impact of snow transparency on fresh snow albedo and neither of the schemes includes the calculation of snow grain size.

\section{Observed results}

\section{a. Observed snow depth and fresh snow albedo}

The histograms of snow depth for the four experimental stations shown in Fig. 1 are presented in Fig. 2. The fraction of winter period (DJF) with snow depth $>1 \mathrm{~cm}$ is labeled, and a few days with snow cover for D105 station occurred from March to June. The snow is quite shallow, except at Dadongshu-Yakou, which is in the Qilian Mountains. The percentage of days with snow depth $<3 \mathrm{~cm}$ during each station's research period exceeds $50 \%$ for
ANNI-AWS, $100 \%$ for D105\%, and $87 \%$ for Tanggula. Even for Dadongshu-Yakou, days with snow depth $<3 \mathrm{~cm}$ still amount to $30 \%$ of the total snow-cover days. These observed snow depths are in agreement with Qin et al. (2006), who noted that the snow on the interior of the TP is quite shallow, usually less than $3 \mathrm{~cm}$.

Within the hourly or half-hourly observations averaged over 1000-1400 local time, a snowfall case (a day with snowfall) should meet the following requirements: 1) the averaged air temperature is $<5^{\circ} \mathrm{C}, 2$ ) the precipitation amount $>0$, and 3) the averaged snow depth increases compared with the previous day. To investigate the albedo characteristics of fresh snow on shallow snowpack or bare ground, we show in Fig. 3 the surface albedo change after all snowfall events for the four experimental stations where surface albedo was $<0.3$ before snowfall. The snowfall events are represented by spikes. Current snow schemes set a fixed fresh snow albedo of 0.7-0.9, which is in agreement with the black spikes plotted in Fig. 3 describing an albedo increase to more than 0.7. However, most of the changes in albedo are much less, ranging from 0.1 to 0.4 , as indicated by the colored spikes. In total across the four stations, 78 of the 94 albedo changes were gradual increases in albedo rather than an immediate jump to 0.7 or more. For ANNI-AWS, only 1 of the 5 cases shows a sharp increase of albedo with the other 4 cases presenting gradual increases. For D105, there is only one snowfall case, which shows a rather small increase $(<0.1)$ of fresh snow albedo. For Tanggula, only 2 of the 25 snowfall cases show a sharp albedo increase and all the remaining are 


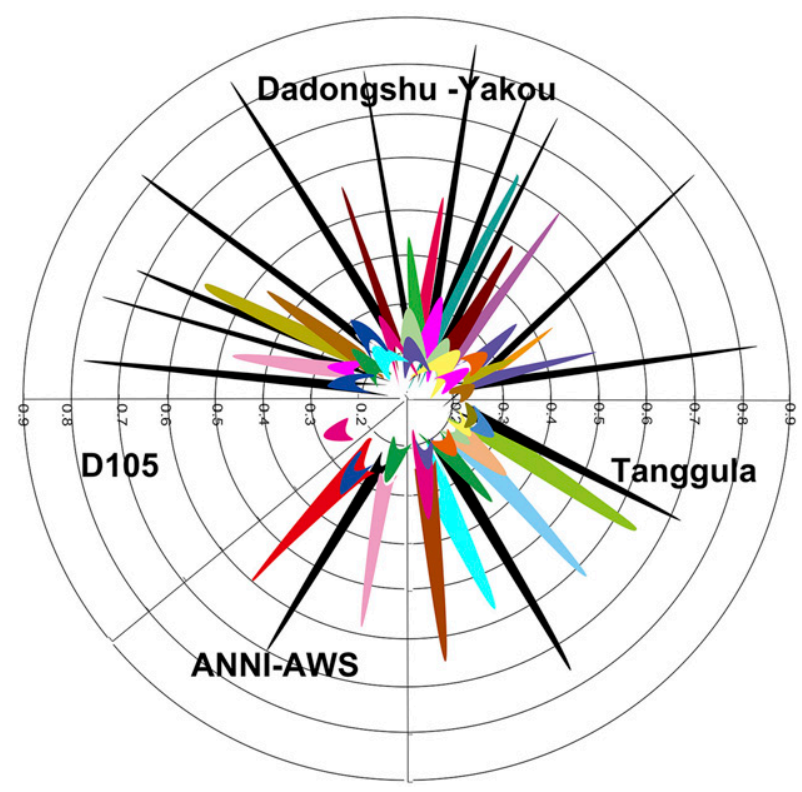

FIG. 3. The change of surface albedo (along radial coordinate) after snowfall episodes. A sector denotes one station. Each spike denotes one snowfall event, with its start and tail representing the albedo before snowfall and after snowfall, respectively. The black spikes represent cases when the fresh snow albedo reached 0.7 or more after snowfall, and the colored spikes represent the cases when the fresh snow albedo increased by a small step. Note the figure only shows the cases of ground albedo $<0.3$ before snowfall to ensure that snowfall occurs on shallow snow surface or bare ground.

with a gradual change. For the 63 snowfall cases at Dadongshu-Yakou station, 13 cases are with a sharp albedo increase and 50 cases are with a gradual change. In general, surface albedo gradual increases after snowfall on the TP rather than undergoing an abrupt change to high albedo.

The distribution of fresh snow albedo is shown in Fig. 4. Over $30 \%$ of snowfall cases produce a fresh snow albedo below 0.5. Clearly, the fresh snow albedo on the TP is far below the default value $(\sim 0.8)$ used in most of the current snow schemes.

\section{b. Observed relationship between fresh snow albedo and snow depth}

In this section we explored the factors that affect the fresh snow albedo. In addition to the snow depth mentioned in Giddings and LaChapelle (1961), air temperature and water vapor also drive the growth of snow grain (Rasmus 2005) and affect albedo. We therefore looked into the correlation coefficients between fresh snow albedo and each of air temperature, relative humidity and snow depth, which are shown in Table 2 . The correlation coefficient at ANNI-AWS, and D105 is not defined, as the sample size is too small (see Fig. 2).

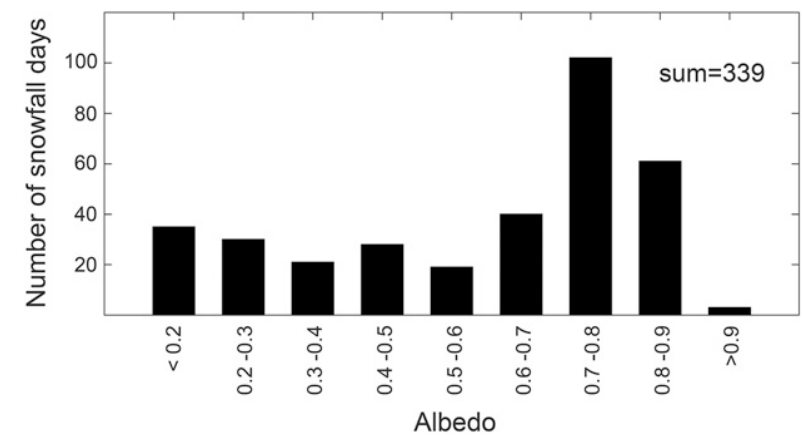

FIG. 4. The histogram of the fresh snow albedo distribution at all the four stations. The number of total days with snowfall is labeled in the upper-right corner. The statistics are based on the data of all the snowfall days.

Significant correlations at both remaining stations only occur between fresh snow albedo and snow depth. For Dadongshu-Yakou and Tanggula, the correlation coefficient is 0.61 and 0.79 , respectively. As might be expected, relative humidity is a significant factor at the high snowaccumulation Dadongshu-Yakou site, and surface temperature at the low snow-accumulation Tanggula station. Snow depth is therefore the dominant factor determining fresh snow albedo at both high and low accumulation sites, and the deeper the snow depth $(<4 \mathrm{~cm})$, the higher the fresh snow albedo.

Figure 5 shows the boxplot of fresh snow albedo varying with respect to snow depth. Again, the snowfall cases with snow depth $>1 \mathrm{~cm}$ are very limited for ANNIAWS and D105, and thus they are not shown in Fig. 5. The boxplot for each station shows the range of fresh snow albedo within the individual snow-depth categories. When the snow depth is less than $4 \mathrm{~cm}$, the fresh snow albedo of Dadongshu-Yakou in more than half of the snowfall cases remains below 0.4, although it occasionally reaches 0.8 or more; when the snow is thicker than $4 \mathrm{~cm}$, the albedo in more than half of the snowfall cases is higher than 0.7 and occasionally drops below 0.5 . The fresh snow albedo at Tanggula shows an obvious increase with respect to snow depth when snow depth is less than about $5 \mathrm{~cm}$. The results of the TP stations are consistent with the much earlier finding in the Arctic, that several centimeters of snow are required for the albedo of freshly fallen snow to reach an asymptotic high value (Giddings and LaChapelle 1961).

The existence of high albedo values in thin snow cases or low albedo values in thick snow cases indicates that second-order factors can also affect the fresh snow albedo. For example, increased cloud fraction will change the solar spectral distribution (i.e., after passing through clouds, the energy ratio of visible band to near-infrared band increases) and therefore enhance snow surface 
TABLE 2. The partial correlation between fresh snow albedo and environmental conditions. The correlation with $p$ value $<0.001$ is marked with an asterisk. The sample size for ANNI-AWS and D105 is too small and thus the correlation is not shown at the two stations.

\begin{tabular}{lcccc}
\hline \hline \multicolumn{1}{c}{ Station } & $\begin{array}{c}\text { Sample } \\
\text { size }\end{array}$ & $\begin{array}{c}\text { Snow } \\
\text { depth }\end{array}$ & $\begin{array}{c}\text { Air } \\
\text { temperature }\end{array}$ & $\begin{array}{c}\text { Relative } \\
\text { humidity }\end{array}$ \\
\hline Dadongshu-Yakou & 63 & $0.61^{*}$ & 0.12 & $0.19^{*}$ \\
Tanggula & 25 & $0.79^{*}$ & $-0.45^{*}$ & 0.07 \\
\hline
\end{tabular}

albedo. However, although important, investigation on these second-order factors is beyond the scope of this study and is expected to be addressed in future.

\section{Simulated snow albedo-snow depth relationship}

First, SNICAR is demonstrated to be capable of reproducing the observed dynamics at the four experimental stations. Then, the SNICAR-simulated albedo values are used to support the development of a simple fresh snow albedo scheme.

\section{a. SNICAR-simulated dependence of fresh snow albedo on snow depth and grain size}

Snow grain size is an important snowpack variable influencing the albedo is. It is the effective snow grain radius or diameter if the ice crystal is nonspherical (Grenfell and Warren 1999) that is represented by a collection of spheres with the same volume-to-area ratio. Considering snow albedo is greatly affected by the snow grain size as well as snow depth, we run SNICAR with a group of snow depth values ranging from 0.1 to $20 \mathrm{~cm}$ and snow grain diameters ranging from 20 to $1000 \mu \mathrm{m}$. The results are shown by the symbols in Fig. 6 . The observed increase of fresh snow albedo with respect to snow depth shown in Fig. 5 can be approximately reproduced by SNICAR.

\section{b. Development of a fresh snow albedo scheme}

Weather forecasting and climate modeling usually require time-saving parameterization schemes. We therefore made efforts to simplify SNICAR and derived a parameterization which is an approximate relationship between fresh snow albedo, snow grain size and snow depth (Fig. 6).

The scheme is a heuristic one, which consists of two terms: one is the back scattering when solar radiation penetrates the snow, and the other is the forward scattering for the reflected solar radiation from the ground surface. The scheme is given below:

$$
\mathrm{alb}_{\text {snow }}=\beta_{1} \times\left(1-e^{-2 k z}\right)+\beta_{2} \times\left(e^{-2 k z}\right),
$$

(a) Tanggula

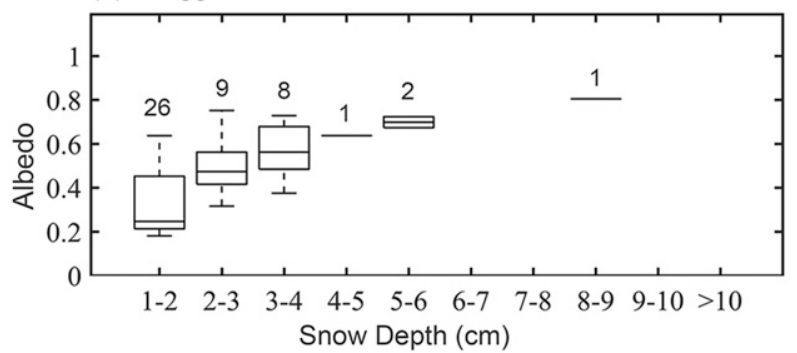

(b) Dadongshu-Yakou

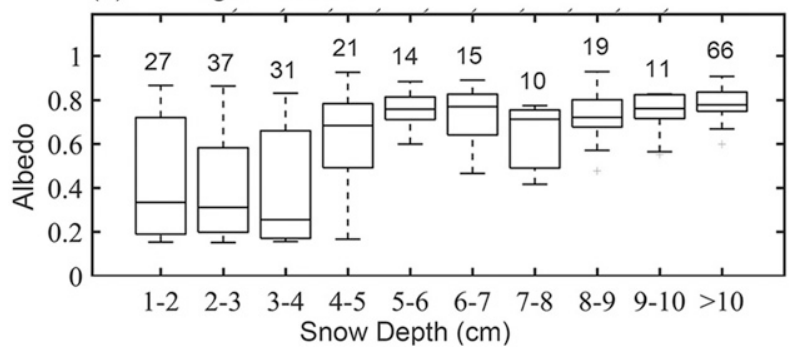

FIG. 5. Boxplot of fresh snow albedo with respect to snow depths at Tanggula and Dadongshu-Yakou station. The number of days with snowfall at each snow depth category is labeled above the box. The statistics are based on the data of all the snowfall days with snow depth $\geq 1 \mathrm{~cm}$. ANNI-AWS and D105 are not presented because their sample sizes are too small.

where $a b_{\text {snow }}$ is the fresh snow albedo, $z$ is the snow depth $(\mathrm{cm}), k$ is the extinction coefficient $\left(\mathrm{cm}^{-1}\right)$ that describes the absorption and scattering capability of the snowpack.

Considering two extreme conditions-1) $\mathrm{alb}_{\text {snow }}=$ $\mathrm{alb}_{\infty}$ if $z$ approaches infinite snow depth, where $\mathrm{alb}_{\infty}$ is the albedo of fresh semi-infinite snow, and 2) alb $\mathrm{anow}_{\text {snow }}=$ alb ground if $z=0$, where alb ground is the background albedo (i.e., the albedo of the old snow or the snow-free ground before snowfall) - we can determine $\beta_{1}=\mathrm{alb}_{\infty}$, $\beta_{2}=\mathrm{alb}_{\text {ground }}$. Therefore,

$$
\mathrm{alb}_{\text {snow }}=\mathrm{alb}_{\infty} \times\left(1-e^{-2 k z}\right)+\mathrm{alb}_{\text {ground }} \times\left(e^{-2 k z}\right),
$$

$\mathrm{alb}_{\infty}$ and the extinction coefficient $k$ are dependent on snow grain size. Based on the SNICAR simulated albedo values, alb $b_{\infty}$ and $k$ are parameterized as follows:

$$
\begin{aligned}
\mathrm{alb}_{\infty} & =a \times \ln \left(D_{\mathrm{snw}}\right)+b, \\
k & =c \times D_{\mathrm{snw}}^{d},
\end{aligned}
$$

where $D_{\text {snw }}$ is the snow grain size in $\mu \mathrm{m}$. Parameters $a, b, c$, and $d$ are the regression coefficients and were fitted by the SNICAR simulations. The fitted values are presented in Table 3. 

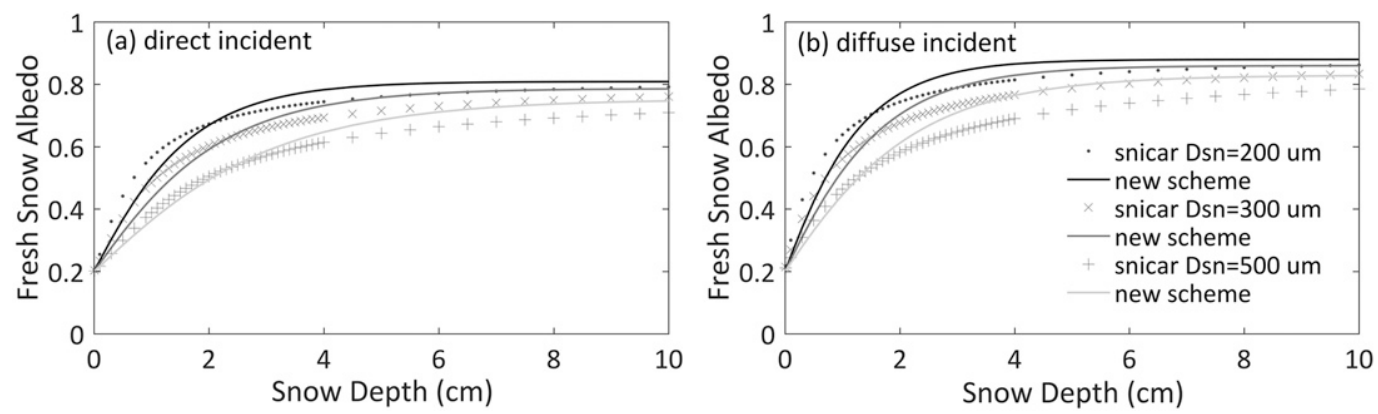

FIG. 6. The change of fresh snow albedo with respect to snow depth and different grain sizes, with (a) direct radiation and (b) diffuse radiation, simulated with SNICAR (symbols) and estimated by the new fresh snow albedo scheme (lines).

Other processes like blowing snow and dust deposition could also decrease the snow albedo (Rasmus 2005), and there is space to work further on the current scheme.

\section{Impact of depth-dependent fresh snow albedo on snow ablation}

We tested the impact of fresh snow albedo on the Tibetan snow processes using the Noah-MP (Niu et al. 2011). The new fresh snow albedo scheme derived in section $4 \mathrm{~b}$ considers the impact of snow grain size, but the original snow schemes in Noah-MP (BATS and CLASS) do not provide this parameter. To demonstrate the impact of fresh snow albedo on snow ablation, we introduced a new set of snow albedo scheme in this study, which consists of the derived new fresh snow albedo scheme, the snow grain size scheme from Anderson (1976) as function of dewpoint temperature and the snow aging scheme from Baker et al. (1990) and Verseghy (1991). The details of snow grain size and snow aging schemes used in this study are listed in the appendix.

The model was run with this introduced snow albedo scheme which includes snow aging and grain size calculation. We also made a simulation with a fixed fresh snow albedo. The simulations were conducted at the 45 TP meteorological stations as shown in Fig. 1 over the period of 2012-14. Because of uncertainties in measuring snowfall and snow depth, the averaged snow depth across the 45 stations was used to validate the simulations. Since the observed precipitation does not distinguish snowfall and rainfall, a precipitation partition scheme based on air temperature, relative humidity and elevation (Ding et al. 2014, 2017) was used in this study.

The new fresh snow albedo scheme exerts a considerable impact on the snow depth on the TP. The simulated time series of daily mean snow depth from 2012 to 2014 was validated with station-averaged observation in
Fig. 7. The simulation with the new fresh snow albedo fitted quite well with the observation in both the 2012-13 snow season when there are many snowfall events and the 2013-14 snow season when there are fewer snowfall events. In contrast, the simulation with the fixed fresh snow albedo of 0.82 overestimated snow during the snow ablation period in both the 2012-13 snow season and the 2013-14 snow season based on the averaged snow depth across 45 stations. The new fresh snow albedo is clearly a controlling factor in the snow ablation simulation.

Nevertheless, we found that the difference between the simulations in winter (DJF) is much less than the difference in spring (MAM). We analyzed the energy budget process in winter and in spring (not shown). The results showed that snow sublimation instead of melting dominates the snow ablation in winter. The absorbed solar radiation is used to warm the snow surface but the surface temperature still cannot reach the melting point, and thus more solar radiation absorbed by the surface in the new scheme is used to increase sensible heat flux and upward longwave radiation. Therefore, the snow depth between the two simulations is similar to each other in winter. However, in spring, the snow surface temperature increases to the melting point and thus the more solar radiation absorbed by the surface in the new scheme is mainly used for snow melting, causing large difference in snow depth between the two simulations.

We also compared the simulated results using the two original snow albedo schemes in Noah-MP with the observed snow depth, as presented in Fig. 8. Although the snow aging process is more complex in BATS, the

TABLE 3. The fitted parameter values for the semi-infinite fresh snow albedo $\left(\mathrm{alb}_{\infty}\right)$ and the extinction coefficient $(k)$ in the fresh snow albedo scheme.

\begin{tabular}{lcccc}
\hline \hline & $a$ & $b$ & $c$ & $d$ \\
\hline Direct radiation & -0.059 & 1.1132 & 23.939 & -0.629 \\
Diffuse radiation & -0.052 & 1.1456 & 10.361 & -0.484 \\
\hline
\end{tabular}



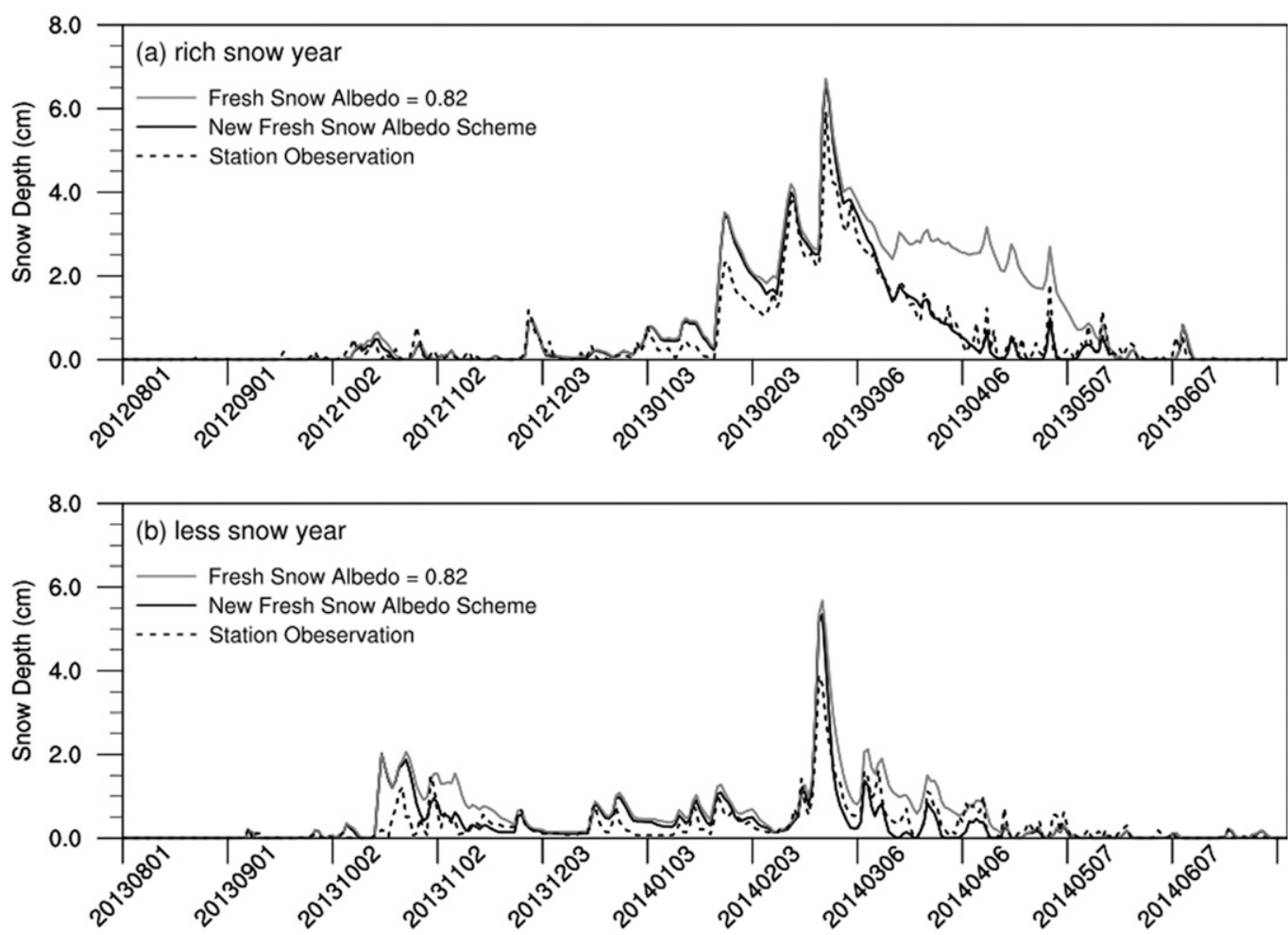

FIG. 7. The comparison of the observed and Noah-MP simulated snow depth averaged across the 45 TP meteorological stations from 2012 to 2014: (a) 1 Aug 2012-31 Jul 2013, with more snow events; (b) 1 Aug 2013-31 Jul 2014, with less snow events. The sensitive simulation is performed with a new snow albedo scheme consisting of one fresh snow albedo scheme derived in this study or a fixed fresh snow albedo as 0.82 , and the snow grain size and snow aging schemes developed by Anderson (1976).

simulated snow depth is very similar to the one simulated with the fixed fresh snow albedo in Fig. 7. The CLASS scheme outperforms BATS in the simulation because CLASS calculates the fresh snow albedo as the weighted average of the old snow albedo at the previous step and 0.84 when the new snowfall mass is $<1 \mathrm{~mm}$. This again confirms that the ground visibility impacts fresh snow albedo and impacts much the snow ablation on TP. However, since CLASS sets a lower bound of snow albedo as 0.55 , it still significantly overestimates the snow depth during the snow ablation period based on the averaged results across 45 stations.

\section{Conclusions and discussion}

This study investigated the characteristics of fresh snow albedo in the TP interior and its effect on the snow ablation. According to experimental station data, snow is quite thin on the TP interior and the albedo of freshly fallen snow cannot reach 0.7 unless the snow depth reaches around $4 \mathrm{~cm}$. This relationship can be reproduced by the physics-based radiative transfer model SNICAR. However, this fact is not well supported in parameterizations of snow albedo used in most of current land surface models, in which a fixed high value for fresh snow albedo is usually assumed regardless of the snow depth. Therefore, a new scheme was developed to account for the relationship between fresh snow albedo, snow grain size and snow depth based on SNICAR simulations.

The impact of the fresh snow albedo on the snow ablation was then investigated with the land surface model Noah-MP over 45 TP meteorological stations, using either a fixed high value of fresh snow albedo or the new fresh snow albedo scheme, or each of two original snow albedo schemes in Noah-MP. The results are validated with station observed daily snow depth. The modeling revealed that the fresh snow albedo that considers the impact of snow depth is a controlling factor in the snow ablation simulation. The simulated TP station snow depth corresponded well with the observation when the new fresh snow albedo scheme was applied. The simulation with the fixed fresh snow albedo, however, simulated too much snow in the snow ablation period based on the averaged snow depth across 45 TP stations. The simulations with both the 

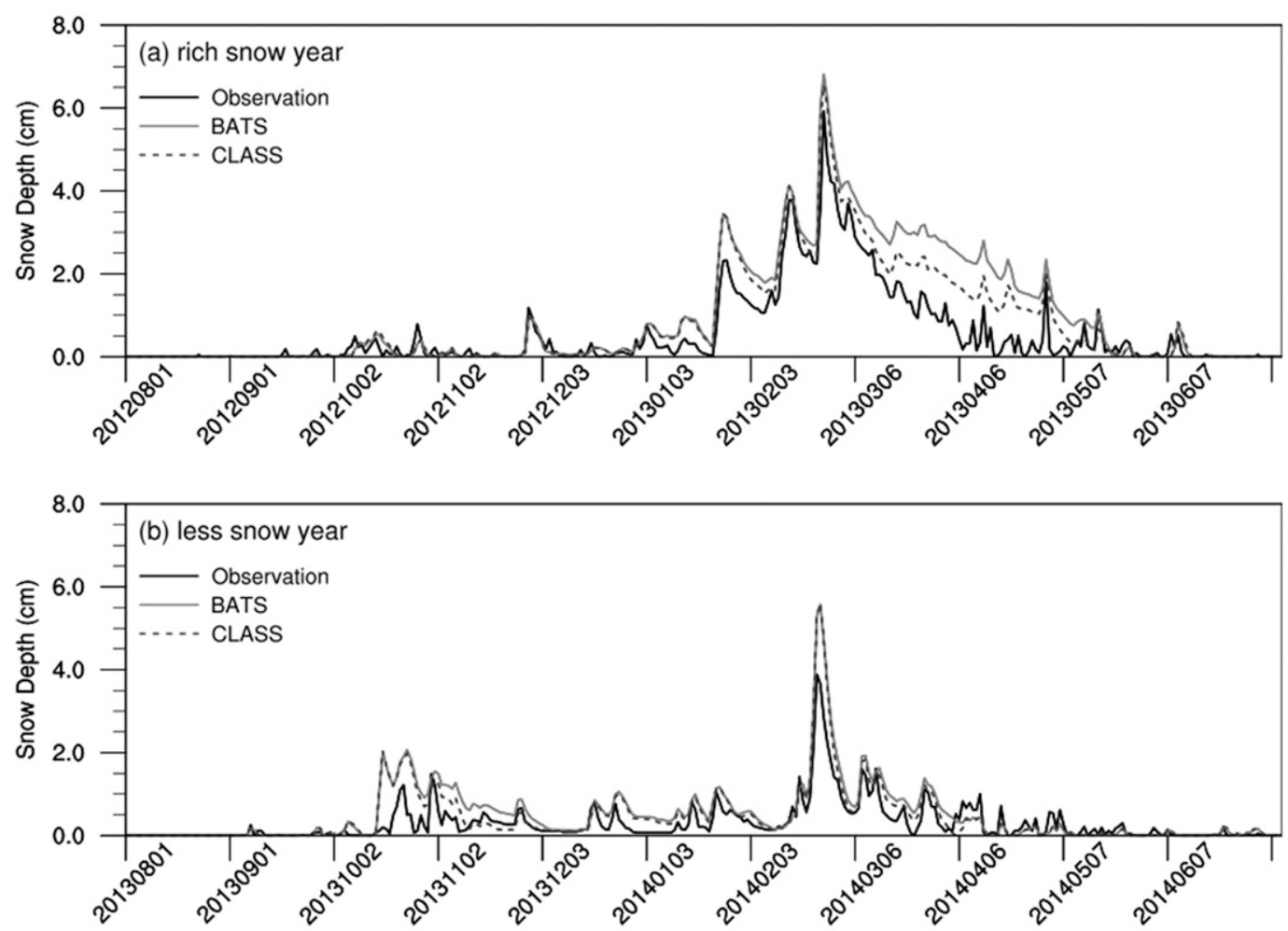

FIG. 8. As in Fig. 7, but compared with two default snow albedo schemes in Noah-MP.

original snow albedo schemes in Noah-MP are poorer than the one with the new fresh snow albedo scheme. This confirmed the importance of considering snow depth impact on fresh snow albedo.

Other factors in addition to snow depth and grain size can affect fresh snow albedo, too. Cold weather favors high albedo snow (Rasmus 2005; Armstrong and Brun 2008), whereas warm and moist air tends to lower the albedo due to the larger size of snow grain (Rasmus 2005). Clouds also produce effects on snow albedo by modifying the spectrum of solar radiation (i.e., cloud absorbs less visible energy than near-infrared energy), which causes snow broadband albedo higher (Salby 1996). Impurities such as black carbon and dust can greatly reduce the snow albedo in the marginal area of the TP. All these factors likely contribute to scatter in the observed relationship between fresh snow albedo and snow depth (see Fig. 5), and they should be accounted for in follow-on fresh snow albedo scheme development.

In summary, this study revealed the fresh snow albedo as a key factor in snow ablation on the interior of the $\mathrm{TP}$, where the snow is rather thin and the radiation is strong. The absence of the dependence of fresh snow albedo on snow depth in the current snow schemes could potentially cause large overestimation of snow depth in state-of-the-art reanalysis datasets. Implementation of the relationship between fresh snow albedo and snow depth in reanalysis systems can be helpful to understand the overestimation of snow depth on the Tibetan Plateau. This has implications both for analyzing snow cover and water resources under climate change scenarios, and for reconstructing past environments on TP in paleoclimate simulations.

Acknowledgments. This work was supported by National Key Research and Development Program of China (Grant 2017YFA0603703), National Science Foundation of China (Grant 91537210), Frontier Science Project of Chinese Academy of Sciences (Grant QYZDYSSW-DQC011-03), and Project supported by the National Science Foundation for Young Scientists of China (Grant 41901075).

Data availability statement: The observed data under CAMP and of Dadongshu-Yakou station is available at http://data.tpdc.ac.cn/en/data/8028b944-daaa4511-8769-965612652c49/, the website of National Tibetan Plateau Data Center. The observed data of Tanggula station is provided by the Cryosphere Research Station on Qinghai-Xizang Plateau, Chinese Academy of Sciences and is available at http://www.crs.ac.cn. The daily meteorological observations is provided by the 
National Meteorological Information Center of Chinese Meteorological Administration (CMA).

\section{APPENDIX}

\section{Snow Schemes}

Two snow albedo schemes in Noah-MP (i.e., BATS and CLASS), the snow grain size scheme from Anderson (1976) and the snow aging scheme from Baker et al. (1990) and Verseghy (1991) introduced in this study are listed below.

\section{a. BATS}

For diffuse radiation, the snow albedo alb diffuse is calculated by Eq. (A1), with the fresh snow albedo for visible band being 0.95 and for near-infrared band being 0.65 :

$$
\left\{\begin{array}{l}
\mathrm{alb}_{\text {diffuse }_{\text {vis }}}=0.95 \times\left(1-0.2 \times F_{\text {age }}\right) \\
\text { alb }_{\text {diffuse }_{\text {nir }}}=0.65 \times\left(1-0.5 \times F_{\text {age }}\right)
\end{array} .\right.
$$

For the direct radiation, the snow albedo alb direct is calculated by Eq. (A2):

$$
\left\{\begin{array}{l}
\mathrm{alb}_{\text {direct }_{\text {vis }}}=\mathrm{alb}_{\text {diffuse }_{\text {vis }}}+0.4 \times F_{\text {zenith }} \times\left(1-\mathrm{alb}_{\text {diffuse }_{\text {vis }}}\right) \\
\mathrm{alb}_{\text {direct }_{\text {nir }}}=\mathrm{alb}_{\text {diffuse }_{\text {nir }}}+0.4 \times F_{\text {zenith }} \times\left(1-\mathrm{alb}_{\text {diffuse }_{\text {nir }}}\right)
\end{array},\right.
$$

where $F_{\text {zenith }}$ is a factor to account for solar zenith angle impact, calculated as Eq. (A3):

$$
F_{\text {zenith }}=\max \left\{\frac{1.5}{[1+\cos (\text { zenith angle })]}-0.5,0\right\} \text {. }
$$

Parameter $F_{\text {age }}$ is a factor to account for snow aging and calculated as Eqs. (A4)-(A10):

$$
\arg =5000\left(\frac{1}{\text { TFRZ }}-\frac{1}{\mathrm{TG}}\right),
$$

$$
\begin{aligned}
& \int \text { Age }_{1}=\exp (\arg ) \\
& \left\{\mathrm{Age}_{2}=\min [1, \exp (10 \times \arg )]\right. \text {, } \\
& \mathrm{Age}_{3}=0.3 \\
& \delta_{a}=10^{-6} \times d t \times\left(\mathrm{Age}_{1}+\mathrm{Age}_{2}+\mathrm{Age}_{3}\right), \\
& \delta_{s}=\max \frac{\left(0, \mathrm{swe}^{t}-\mathrm{swe}^{t-1}\right)}{\mathrm{swe}_{c}}, \\
& \operatorname{sge}^{t}=\left(\operatorname{tauss}^{t-1}+\delta_{a}\right) \times\left(1-\delta_{s}\right), \\
& \operatorname{tauss}^{t}= \begin{cases}0, & \text { if } \mathrm{swe}^{t}=0 \text { or swe } \\
\max \left(0, \mathrm{sge}^{t}\right), & \text { others }\end{cases}
\end{aligned}
$$

$$
F_{\text {age }}=\frac{\text { tauss }^{t}}{\left(\operatorname{tauss}^{t}+1\right)},
$$

where TFRZ is the freezing temperature set as $273.16 \mathrm{~K}$ in Noah-MP, TG is the ground temperature $(\mathrm{K})$, and swe $^{t}$ and swe $\mathrm{s}^{t-1}$ are the snow water equivalents of the current time step and the previous time step. Parameter swe $_{c}$ is the critical value of new snow water equivalent to fully cover the old snow, assumed to be $1 \mathrm{~mm}$. Parameter $d t$ is the time step (s) in Noah-MP.

\section{b. CLASS}

CLASS assumes an identical snow albedo for both direct and diffuse radiation. When there is snowfall and the snow depth surpasses $1 \mathrm{~cm}$, the fresh snow albedo is 0.84 ; otherwise, the fresh snow albedo is calculated as the weighted average of 0.84 and the albedo of the underground before snowfall, as in Eq. (A11):

$$
\mathrm{alb}=\mathrm{alb}_{\mathrm{old}}^{t}+\frac{\min \left(Q_{\text {snow }} \times d t, \mathrm{swe}_{c}\right) \times\left(0.84-\mathrm{alb}_{\mathrm{old}}^{t}\right)}{\mathrm{swe}_{c}},
$$

where alb is the snow albedo, $\mathrm{alb}_{\text {old }}^{t}$ is the snow albedo before snowfall, swe $_{c}=1 \mathrm{~mm}$ is the critical value of new snow water equivalent that fully covers the old snow, $Q_{\text {snow }}$ is the snowfall rate $\left(\mathrm{mm} \mathrm{s}^{-1}\right)$, and $d t$ is the modeling time step (s).

The snow albedo is assumed to be no less than 0.55. The snow aging is expressed by an exponential function of the modeling time step $d t$,

$$
\mathrm{alb}_{\text {old }}^{t}=0.55+\left(\mathrm{alb}_{\text {old }}^{t-1}-0.55\right) \times \exp \left(\frac{-0.01 \times d t}{3600}\right),
$$

where $\mathrm{alb}_{\text {old }}^{t-1}$ is the snow albedo before snowfall at the last time step.

\section{c. Introduced snow grain size and snow aging schemes in this study}

This study introduced a new snow albedo scheme, which is a combination of a derived fresh snow albedo scheme described in detail in section $4 \mathrm{~b}$ and the snow grain size scheme from Anderson (1976) and the snow aging scheme from Baker et al. (1990) and Verseghy (1991). Note that BATS and CLASS are not used in the new scheme because they do not calculate snow grain size which is needed in the new scheme.

The snow grain diameter is calculated as follows:

$$
D_{\mathrm{sn}}=\left\{\begin{array}{ll}
2.796 \times 10^{-3} & \rho_{\mathrm{sn}} \geq 400 \\
1.6 \times 10^{-4}+1.1 \times 10^{-13} \times \rho_{\mathrm{sn}}^{4} & 0<\rho_{\mathrm{sn}}<400
\end{array},\right.
$$




$$
\rho_{\mathrm{sn}}= \begin{cases}169 & T_{w}>2 \\ 50+1.7\left(T_{w}+14.99\right)^{1.5} & -15<T_{w} \leq 2, \\ 50 & T_{w} \leq-15\end{cases}
$$

(A14) where $D_{\mathrm{sn}}$ is the snow particle diameter in $\mu \mathrm{m}, \rho_{\mathrm{sn}}$ is snow density in $\mathrm{kg} \mathrm{m}^{-3}$, and $T_{w}$ is the dewpoint temperature in ${ }^{\circ} \mathrm{C}$.

Snow aging is calculated by

$$
\mathrm{alb}= \begin{cases}\max \left(\mathrm{alb}-\tau_{a} \times \frac{d t}{86400}, \mathrm{alb}_{\text {soil }}\right), & \text { Non-melting condition } \\ \left(\mathrm{alb}-\mathrm{alb}_{\mathrm{soil}}\right) \times e^{\left(-\tau_{f} \times \frac{d t}{86400}\right)}+\mathrm{alb}_{\text {soil }}, & \text { Melting condition }\end{cases}
$$

where alb is the snow albedo, alb soil $_{\text {in }}$ is the soil albedo, and $d t$ is the modeling time step (s). Parameters $\tau_{f}$ and $\tau_{a}$ are scaling parameters that are set to 0.24 and 0.008 , respectively, according to Sun et al. (1999).

\section{REFERENCES}

Anderson, E. A., 1976: A point energy and mass balance model of a snow cover. NOAA Tech. Rep. NWS 19, 150 pp., http:// amazon.nws.noaa.gov/articles/HRL_Pubs_PDF_May12_2009/ HRL_PUBS_51-100/81_A_POINT_ENERGY_AND_MASS.pdf.

Armstrong, R. L., and E. Brun, 2008: Snow and Climate: Physical Processes, Surface Energy Exchange and Modeling. Cambridge University Press, 222 pp.

Baker, D. G., D. L. Ruschy, and D. B. Wall, 1990: The albedo decay of prairie snows. J. Appl. Meteor., 29, 179-187, https:// doi.org/10.1175/1520-0450(1990)029<0179:TADOPS $>$ 2.0.CO;2.

Blanford, H. F., 1884: On the connexion of Himalayan snowfall with dry winds and seasons of drought in India. Proc. Roy. Soc. London, 37, 3-22, https://doi.org/10.1098/rspl.1884.0003.

Che, T., X. Li., R. Jin, R. Armstrong, and T. J. Zhang, 2008: Snow depth derived from passive microwave remote-sensing data in China. Ann. Glaciol., 49, 145-154, https://doi.org/10.3189/ 172756408787814690.

_ - and Coauthors, 2019: Integrated hydrometeorological, snow and frozen-ground observations in the alpine region of the Heihe River Basin, China. Earth Syst. Sci. Data, 11, 1483 1499, https://doi.org/10.5194/essd-11-1483-2019.

Chen, F., and Coauthors, 1996: Modeling of land-surface evaporation by four schemes and comparison with FIFE observations. J. Geophys. Res., 101, 7251-7268, https://doi.org/10.1029/ 95JD02165.

Dai, Y. J., X. Zeng, and R. E. Dickinson, 2001: The Common Land Model (CLM): Technical documentation and user's guide. Georgia Institute of Technology, $69 \mathrm{pp}$.

Dickinson, R. E., A. Henderson-Sellers, and P. J. Kennedy, 1993: Biosphere-Atmosphere Transfer Scheme (BATS) Version 1e as coupled to the NCAR Community Climate Model. NCAR Tech. Note NCAR/TN-387+STR, 88 pp., https://doi.org/ 10.5065/D67W6959.

Ding, B., K. Yang, J. Qin, L. Wang, Y. Chen, and X. He, 2014: The dependence of precipitation types on surface elevation and meteorological conditions and its parameterization. J. Hydrol., 513, 154-163, https://doi.org/10.1016/j.jhydrol.2014.03.038.
— - and Coauthors, 2017: Development of a Water and Enthalpy Budget-based Glacier mass balance Model (WEB-GM) and its preliminary validation. Water Resour. Res., 53, 3146-3178, https://doi.org/10.1002/2016WR018865.

Douville, H., J. F. Royer, and J. F. Mahfouf, 1995: A new snow parameterization for the Meteo-France climate model. Climate Dyn., 12, 21-35, https://doi.org/10.1007/BF00208760.

Flanner, M. G., and C. S. Zender, 2005: Snowpack radiative heating: Influence on Tibetan Plateau climate. Geophys. Res. Lett., 32, L06501, https://doi.org/10.1029/2004GL022076.

— evolution. J. Geophys. Res., 111, D12208, https://doi.org/ 10.1029/2005JD006834.

- — — - J. T. Randerson, and P. J. Rasch, 2007: Present day climate forcing and response from black carbon in snow. J. Geophys. Res., 112, D11202, https://doi.org/10.1029/ 2006JD008003.

Giddings, J. C., and E. R. LaChapelle, 1961: Diffusion theory applied to radiant energy distribution and albedo of snow. J. Geophys. Res., 66, 181-189, https://doi.org/10.1029/ JZ066i001p00181.

Grenfell, T. C., and S. G. Warren, 1999: Representation of a nonspherical ice particle by a collection of independent spheres for scattering and absorption of radiation. J. Geophys. Res., 104, 31 697-31 709, https://doi.org/10.1029/1999JD900496.

Han, P., D. Long, Z. Han, M. Du, L. Dai, and X. Hao, 2019: Improved understanding of snowmelt runoff from the headwaters of China's Yangtze River using remotely sensed snow products and hydrological modeling. Remote Sens. Environ., 224, 44-59, https://doi.org/10.1016/j.rse.2019.01.041.

He, C., M. G. Flanner, F. Chen, M. Bariage, K. N. Liou, S. Kang, J. Ming, and Y. Qian, 2018: Black carbon-induced snow albedo reduction over the Tibetan Plateau: Uncertainties from snow grain shape and aerosol-snow mixing state based on an updated SNICAR model. Atmos. Chem. Phys., 18,11 507-11 527, https:// doi.org/10.5194/ACP-18-11507-2018.

He, J., K. Yang, W. Tang, H. Lu, J. Qin, Y. Chen, and X. Li, 2020: The first high-resolution meteorological forcing dataset for land process studies over China. Sci. Data, 7, 25, https:// doi.org/10.1038/S41597-020-0369-Y.

IPCC, 2013: Summary for policymakers. Climate Change 2013: The Physical Science Basis, T. F. Stocker et al., Eds., Cambridge University Press, 3-29.

Koike, T., 2004: The coordinated enhanced observing period-An initial step for integrated global water cycle observation. WMO Bull., 53 (2), 1-8. 
Lawrence, D. M., K. W. Oleson, M. G. Flanner, P. E. Thornton, S. C. Swenson, P. J. Lawrence, and G. B. Bonan, 2011: Parameterization improvements and functional and structural advances in Version 4 of the Community Land Model. J. Adv. Model. Earth Syst., 3, M03001, https://doi.org/ 10.1029/2011MS00045.

Li, H., X. Li, D. Yang, J. Wang, B. Gao, X. Pan, Y. Zhang, and X. Hao, 2019: Tracing snowmelt paths in an integrated hydrological model for understanding seasonal snowmelt contribution at basin scale. J. Geophys. Res. Atmos., 124, 8874-8895, https://doi.org/10.1029/2019JD030760.

Liu, X., and B. Chen, 2000: Climatic warming in the Tibetan Plateau during recent decades. Int. J. Climatol., 20, 1729-1742, https:// doi.org/10.1002/1097-0088(20001130)20:14<1729::AID-JOC556> 3.0.CO;2-Y

Ma, Y., and Coauthors, 2005: Diurnal and inter-monthly variation of land surface heat fluxes over the central Tibetan Plateau area. Theor. Appl. Climatol., 80, 259-273, https://doi.org/ 10.1007/s00704-004-0104-1.

McKay, G. A., and D. M. Gray, 1981: The distribution of snowcover. Handbook of Snow, D. M. Gray and D. H. Male, Eds., Pergamon Press, 153-190.

Niu, G. Y., and Coauthors, 2011: The community Noah land surface model with multi parameterization options (Noah-MP): 1. Model description and evaluation with local-scale measurements. J. Geophys. Res., 116, D12109, https://doi.org/ 10.1029/2010JD015139.

Oleson, K. W., and Coauthors, 2010: Technical description of version 4.0 of the Community Land Model (CLM). NCAR Tech. Note NCAR/TN-478+STR, 257 pp., https://doi.org/ 10.5065/D6FB50WZ.

Orsolini, Y., and Coauthors, 2019: Evaluation of snow depth and snow-cover over the Tibetan Plateau in global reanalyses using in-situ and satellite remote sensing observations. Cryosphere, 13, 2221-2239, https://doi.org/10.5194/TC-132221-2019.

Qian, Y., M. G. Flanner, L. R. Leung, and W. Wang, 2011: Sensitivity studies on the impacts of Tibetan Plateau snowpack pollution on the Asian hydrological cycle and monsoon climate. Atmos. Chem. Phys., 11, 1929-1948, https://doi.org/ 10.5194/acp-11-1929-2011.

Qin, D. H., S. Y. Liu, and P. J. Li, 2006: Snow cover distribution, variability, and climate change in western China. J. Climate, 19, 1820-1833, https://doi.org/10.1175/JCLI3694.1.

Rasmus, S., 2005: Snow pack structure characteristics in Finland: Measurements and modelling. Ph.D. dissertation, University of Helsinki, 237 pp.

Salby, M. L., 1996: Fundamentals of Atmospheric Physics. Elsevier, $627 \mathrm{pp}$.

Sellers, P. J., and Coauthors, 1996: A revised land surface parameterization (SiB2) for atmospheric GCMs. Part I: Model formulation. J. Climate, 9, 676-705, https://doi.org/10.1175/ 1520-0442(1996)009<0676:ARLSPF $>2.0 . C O ; 2$.

Shao, D., H. Li, J. Wang, X. Pan, and X. Hao, 2017: Distinguishing the role of wind in snow distribution by utilizing remote sensing and modeling data: Case study in the northeastern Tibetan Plateau. IEEE J. Sel. Top. Appl. Earth Obs. Remote Sens., 10, 4445-4456, https://doi.org/10.1109/JSTARS.2017.2716388.

Singh, D., M. G. Flanner, and E. Millour, 2018: Improvement of Mars surface snow albedo modeling in LMD Mars GCM with
SNICAR. J. Geophys. Res. Planets, 123, 780-791, https:// doi.org/10.1002/2017JE005368.

Sun, J., and Coauthors, 2018: Linkages of the dynamics of glaciers and lakes with the climate elements over the Tibetan Plateau. Earth-Sci. Rev., 185, 308-324, https://doi.org/10.1016/ j.earscirev.2018.06.012.

Sun, S., J. Jin, and Y. Xue, 1999: A simple snow-atmosphere-soil transfer model. J. Geophys. Res., 104, 19587-19597, https:// doi.org/10.1029/1999JD900305.

Toon, O. B., C. P. McKay, T. P. Ackerman, and K. Santhanam, 1989: Rapid calculation of radiative heating rates and photodissociation rates in inhomogeneous multiple scattering atmospheres. J. Geophys. Res., 94, 16 287-16301, https://doi.org/10.1029/ JD094iD13p16287.

Verseghy, D. L., 1991: CLASS-A Canadian land surface scheme for GCMS. I. Soil model. Int. J. Climatol., 11, 111-133, https:// doi.org/10.1002/joc.3370110202.

Wang, J., and Coauthors, 2018: Investigation on snow characteristics and their distribution in China. Adv. Earth Sci., 33, 12-15, https://doi.org/10.11867/j.issn.1001-8166.2018.01.0012.

Wang, W., and Coauthors, 2016: Evaluation of air-soil temperature relationships simulated by land surface models during winter across the permafrost region. Cryosphere, 10, 1721-1737, https://doi.org/10.5194/tc-10-1721-2016.

Wiscombe, W. J., 1980: Improved Mie scattering algorithms. Appl. Opt., 19, 1505-1509, https://doi.org/10.1364/AO.19.001505.

Wu, X., L. Zhao, H. Fang, Y. Zhao, J. M. Smoak, Q. Pang, and Y. Ding, 2016: Environmental controls on soil organic carbon and nitrogen stocks in the high-altitude arid western QinghaiTibetan Plateau permafrost region. J. Geophys. Res. Biogeosci., 121, 176-187, https://doi.org/10.1002/2015JG003138.

Xiao, Z., and A. Duan, 2016: Impacts of Tibetan Plateau snow cover on the interannual variability of the East Asian summer monsoon. J. Climate, 29, 8495-8514, https://doi.org/10.1175/ JCLI-D-16-0029.1.

Yang, K., J. He, W. Tang, J. Qin, and C. C. K. Cheng, 2010: On downward shortwave and longwave radiations over high altitude regions: Observation and modeling in the Tibetan Plateau. Agric. For. Meteor., 150, 38-46, https://doi.org/10.1016/ j.agrformet.2009.08.004.

Yang, Y., K. A. Hopping, G. Wang, J. Chen, A. Peng, and J. A. Klein, 2018: Permafrost and drought regulate vulnerability of Tibetan Plateau grasslands to warming. Ecosphere, 9, e02233, https://doi.org/10.1002/ecs2.2233.

Ye, B., D. Yang, Y. Ding, T. Han, and T. Koike, 2004: A biascorrected precipitation climatology for China. J. Hydrometeor., 5, 1147-1160, https://doi.org/10.1175/JHM-366.1.

Zhang, T., 2005: Influence of the seasonal snow cover on the ground thermal regime: An overview. Rev. Geophys., 43, RG4002, https://doi.org/10.1029/2004RG000157.

Zhao, L., and Y. Sheng, 2019: Permafrost and Its Changes on the Qinghai-Tibetan Plateau, Science Press, 200-237.

—_, and Coauthors, 2017: Support geoscience research, environmental management, and engineering construction with investigation and monitoring on permafrost in the Qinghai-Tibet Plateau, China (in Chinese). Bull. Chin. Acad. Sci., 32, 1159-1168,

Zhou, Y., D. Guo, G. Qiu, G. Cheng, and S. Li, 2000: China Permafrost. Science Press, 232 pp. 